\title{
ANALISA PERAWATAN POMPA SENTRIFUGAL INTAKE B DENGAN MENGGUNAKAN METODE RCM DI PERUMDA AIR MINUM TIRTA TERUBUK KAB. BENGKALIS
}

\author{
Asril $^{1}$, dan Bambang Dwi Haripriadi ${ }^{2}$ \\ 1,2Jurusan Teknik Mesin, Program Studi Sarjana Terapan Teknik Mesin Produksi dan Perawatan \\ Politeknik Negeri Bengkalis, Bengkalis, 28711, Indonesia \\ Email: asrilboy200897@gmail.com
}

\begin{abstract}
Abstrak
Pompa adalah suatu alat (mesin fluida) yang banyak digunakan dalam suatu industri khususnya di industri Perumda Air Minum Tirta Terubuk Kab Bengkalis. Pompa merupakan suatu alat yang dapat memindahkan fluida dari satu tempat ke tempat yang lain melalui suatu media perpipaan dengan cara menambahkan energi pada fluida yang dipindahkan dan berlangsung secara kontinyu. Pompa sentrifugal ini sering mengalami kerusakan kecil maupun besar khusus nya di bagian komponen. Penelitian ini menggunakan metode Reliability Centered Maintainance (RCM). Untuk melakukan analisa perawatan pompa sentrifugal yang di gunakan di Perumda Air Minum Tirta Terubuk Kab Bengkalis. Metode RCM adalah metode yang di gunakan untuk menganalisa perawatan pada komponen-komponen yang mungkin menyebabkan kerusakan pada pompa sentrifugal. Hasil dari analisa didapatkan bahwa komponen-komponen pompa yang kritis berdasarkan diagram yaitu pareto dan fishbone yang terdapat 5 kerusakan dengan nilai Rpn tertinggi. Satu masalah terbesar yang jadi perioritas, perioritas utama dalam menentukan masalah potensi kegagalan pada proses kerusakan komponen pompa yang dipilih berdasarkan diagram pareto. Satu masalah terbesar yang jadi perioritas adalah raber kopling rusak RPN (300) yang berpotensi menjadi kegagalan proses kerusakan komponen pompa
\end{abstract}

Kata Kunci: RCM, Pareto dan Fishbone, Pompa Sentrifugal

\begin{abstract}
Pump is a tool (fluid machine) that is widely used in an industry, especially in the Perumda Terubuk Tirta Terubuk drinking water industry in Bengkalis Regency. A pump is a device that can move fluid from one place to another through a piping medium by adding energy to the fluid that is moved and takes place continuously. These centrifugal pumps often experience minor or major damage, especially in the component parts. This study uses the Reliability Centered Maintainance (RCM) method. To analyze the maintenance of centrifugal pumps used in Perumda Tirta Terubuk Drinking Water, Bengkalis Regency. The RCM method is a method used to analyze maintenance on components that may cause damage to a centrifugal pump. The results of the analysis show that the critical pump components based on the diagram are Pareto and Fishbone which have 5 defects with the highest Rpn value. One of the biggest problems that become priority, the main priority in determining the problem of potential failure in the process of damage to pump components selected based on the Pareto diagram. One of the biggest problems that become a priority is the damaged clutch raber RPN (300) which has the potential to fail the pump component damage process.
\end{abstract}

Keywords: RCM, Pareto and Fishbone, Centrifugal Pump

\section{PENDAHULUAN}

Perumda Air Minum Tirta Terubuk Kab. Bengkalis adalah Perusahaan Daerah Air Minum yang berperan khusus menyalurkan air bersih kepada seluruh kalangan masyarakat yang berada di Kota
Bengkalis. Perumda Air Minum Tirta Terubuk Kab Bengkalis melakukan proses produksi secara terusmenerus selama 24 jam, sehingga peran penting yang harus dilakukan adalah mengutamakan perawatan pompa yang menjadi kunci utama dalam produk air bersih yang harus diberikan kepada seluruh kalangan konsumen. Kegiatan pengecekan kondisi pompa dilakukan sesuai dengan jadwal yaitu 1 minggu

35 Asril, dkk.; Analisa Perawatan Pompa Sentrifugal Intake B Dengan Menggunakan Metode Rcm Di Perumda Air Minum Tirta Terubuk Kab. Bengkalis 
sekali. Berbagai uraian aktivitas pengolahan air bersih yang dijalankan dan banyak pompa-pompa yang digunakan untuk mengolah air baku menjadi air bersih. Dari data yang didapatkan diketahui bahwa pompa sentrifugal sering mengalami masalah kerusakan terhadap komponen-komponen di akibatkan kurang adanya sistem perawatan. Permasalahan yang dihadapi saat ini menjadi perhatian oleh PERUMDA Air Minum Tirta Terubuk Kab. Bengkalis adalah persoalan pada pompa sentrifugal, terutama pada perawatan komponenkomponen yang sering mengalami kerusakan. Potensi kemungkinan kerusakan pada pompa sentrifugal akan berakibat serius pada suplai air yang dapat merugikan perusahaan itu sendiri. Hal inilah yang menjadi alasan perlu menggunakan metode yang mampu menyediakan daftar potensi kerusakan pompa sentrifugal di PERUMDA Air Minum Tirta Terubuk Kab. Bengkalis.

Adapun salah satu tool yang akan digunakan untuk membantu pengendalian pada pompa sentrifugal adalah dengan penerapan Reliability Centered Maintainance (RCM). RCM yaitu dengan cara mengumpulkan data yang menunjang proses analisis tersebut seperti data downtime dan produk yang paling berpengaruh dan pompa-pompa yang digunakan. (Azis, M. T., Suprawhardana, M.S., \& Purwanto,T.P.(2010) [1]. Merancang kegiatan pemeliharaan yang tepat dengan menggunakan metode Reliability Centered Maintenance (RCM). Pompa adalah suatu alat yang digunakan untuk memindahkan suatu cairan dari suatu tempat ke tersebut digunakan untuk mengatasi berbagai hambatan pengaliran. Hambatan pengaliran itu dapat berupa perbedaan tekanan, perbedaan ketinggian atau hambatan gesek, pada prinsipnya, pompa mengubah energi mekanik motor menjadi energi aliran fluida, Energi yang diterima oleh fluida akan digunakan untuk menaikkan tekanan dan mengatasi tahanan yang terdapat pada saluran yang dilalui.

Pompa memiliki dua kegunaan utama tempat lain dengan cara menaikkan tekanan cairan tersebut. Kenaikan tekanan cairan:

1. Memindahkan cairan dari satu tempat ke tempat lainnya (misalnya air dari aquifer bawah tanah ke tangki penyimpan air).

2. Mensirkulasikan cairan sekitar sistem (misalnya air pendingin atau pelumas yang melewati mesin dan komponen).

Pompa juga dapat digunakan pada proses yang membutuhkan tekanan hidraulik yang besar. Hal ini bisa dijumpai antara lain pada alat berat. Dalam operasi, mesin alat berat membutuhkan tekanan discharge yang besar dan tekanan isap yang rendah. Akibat tekanan yang rendah pada sisi isap pompa maka fluida akan naik dari kedalaman tertentu, sedangkan akibat tekanan yang tinggi pada sisi discharge akan memaksa fluida untuk naik sampai pada ketinggian yang diinginkan. Pompa secara umum dapat diklasifikasikan menjadi 2 bagian yaitu pompa kerja positif (positive displacement pump) dan pompa kerja dinamis (non positive displacement рuтp).

\section{METODE PENELITIAN}

Dalam penelitian ini, peneliti tidak menggunakan bahan hanya saja menggunakan alat untuk mendapatkan data-data. Tetapi data yang di dapatkan untuk melakukan penelitian bersumber dari hasil observasi lapangan, yaitu dari data yang di miliki oleh pihak perusahaan dan data yang di himpun dari hasil wawancara dilapangan yaitu di Perumda Air Minum Tirta Terubuk Kab. Bengkalis.Rangkaian kegiatan penelitian dilakukan dengan metode RCM (Reliability Centered Maintainance) perawatan dilakukan pada Pompa sentrifugal intake B unit Waduk Di Perumda Air Minum Tirta Terubuk Kab. Bengkalis. Penelitian ini dilakukan pada bulan maret smpai bulan juni 2020 .

\begin{abstract}
Alat dan Bahan
Pengujian dilakukan pada Pompa sentrifugal intake B unit Waduk Di Perumda Air Minum Tirta Terubuk Kab. Bengkalis. Alat dan bahan pada penelitian ini di tampilkan pada gambar 1 dan pada gambar 2 .
\end{abstract}

\section{Vibration meter}

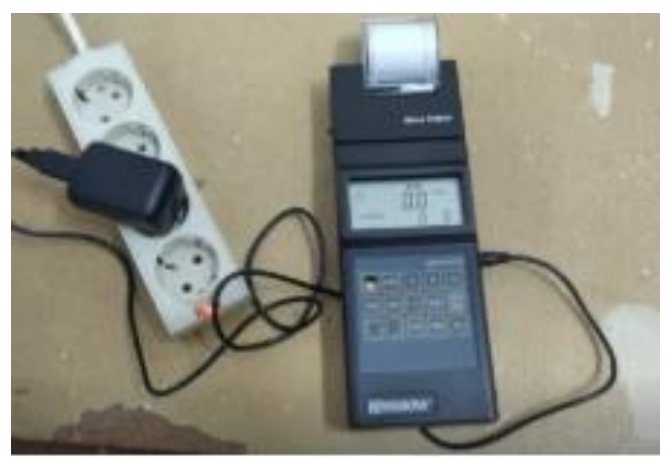

Gambar 1 Vibration Meter

36 Asril, dkk.; Analisa Perawatan Pompa Sentrifugal Intake B Dengan Menggunakan Metode Rcm Di Perumda Air Minum Tirta Terubuk Kab. Bengkalis 


\section{Pompa Sentrifugal}

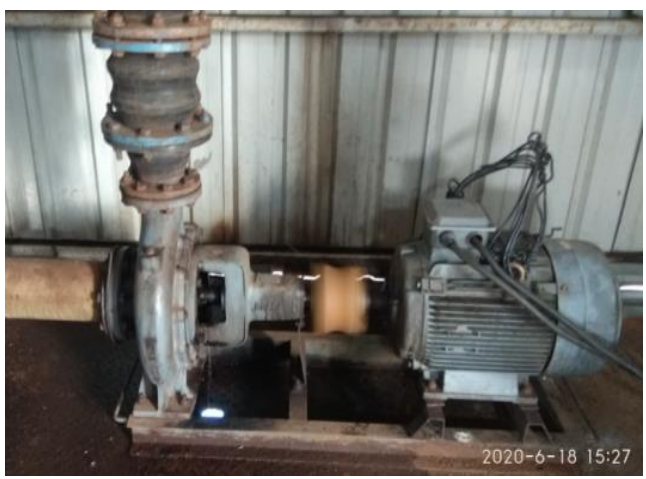

Gambar 2 Pompa Sentrifugal Intake B

Tabel 1 Spesifikasi Pompa

\begin{tabular}{|c|c|}
\hline \multicolumn{2}{|c|}{ NO P171994-25 } \\
\hline \multicolumn{2}{|c|}{ M0DEL 125X100 FS4KA } \\
\hline CAP & 145 \\
\hline HEAD & 30 \\
\hline KW & $1450 \mathrm{RPM}$ \\
\hline \multicolumn{2}{|c|}{ BEARINGS 6307 ZZ } \\
\hline
\end{tabular}

Adapun bahan dan Spesifikasi yang dilakukan perawatan yaitu pompa sentrifugal intake B unit Waduk di Perumda Air Minum Tirta Terubuk Kab. Bengkalis. Spesifikasi pompa sentrifugal yang saya teliti di Perumda Air Minum Tirta Terubuk Kab. Bengkalis dengam no seri No P171994-25 dan ukuran Empeller 125x100 dengan type atau model yang digunakan FS4KA, kapasitas debit air 145 permenit, dengan sekali putaran akan mengahasilkan tekanan 30 meter dengan kecepatan putaran pompa sebesar 1450 RPM dengan menggunakan jenis Bearing 6307 ZZ sesuai dengan standar pompa yang digunakan.

\section{Diagram Alir}

Adapun diagram alir yang digunakan untuk mejelaskan proses yang di kerjakan dalam penelitian ini yang dikerjakan diperlihatkan pada gambar 3 .

\section{Teknik pengumpulan dan analisa data}

Teknik pengumpulan data dilakukan pada Perumda Air Minum Tirta Terubuk Kab. Bengkalis. Teknik yang digunakan adalah sebagai berikut:

1. Observasi

Teknik observasi adalah teknik pengumpulan data dengan cara melakukan pengamatan secara langsung dilapangan.

2. Interview

Metode interview yaitu metode pengumpulan data dengan cara melakukan diskusi dengan operator dan maentenance lapangan.

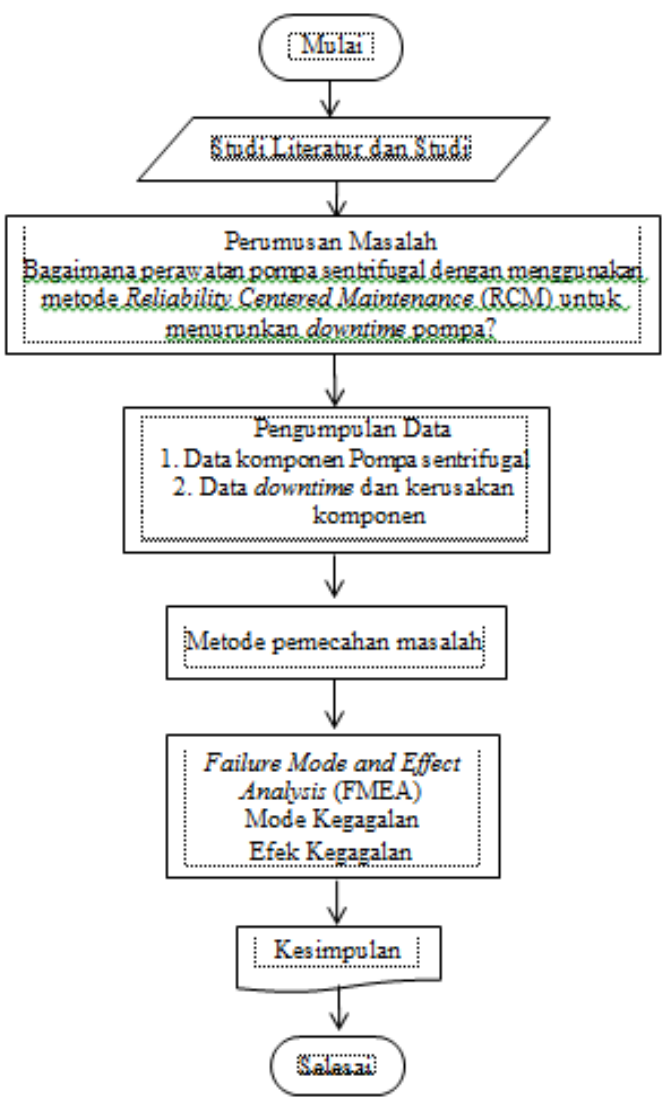

Gambar 3 Diagram Alir

\section{HASIL DAN PEMBAHASAN}

Penelitian ini dilakukan di Perumda Air Minum Tirta Terubuk Kab. Bengkalis dengan mengamati kelengkapan pada pompa sentrifugal intake B untuk mengetahui mode kegagalan dan faktor penyebab pada pompa sentrifugal intake B dengan menggunakan metode RCM untuk memperkirakan potensi dampak yang akan terjadi sehingga dapat mencari jalan keluar dari kegagalan pada pompa sentrifugal intake B. Pengolahan data ini menggunakan metode RCM bertujuan untuk memastikan beberapa sistem fisik berfungsi terus menerus sesuai keinginan operator sekarang ini. Keuntungan pendekatan RCM adalah kegiatan perawatan yang di lakukan menjadi lebih efektif dikarenakan waktu downtime yang berkurang dan waktu penggunaan pompa akan semakin maksimal di gunakan. Untuk mendapatkan komponen-komponen yang kritis yang merupakan resiko-resiko yang akan di analisa lebih lanjut.

Adapun tujuan dalam penelitian ini adalah sebagai berikut: 
1. Untuk mengetahui penyebab kegagalan yang terjadi pada pompa sentrifugal intake $\mathrm{B}$ di Perumda Air Minum Tirta Terubuk Kab. Bengkalis.

2. Untuk mengetahui apa saja upaya yang dilakukan untuk mengurangi tingkat kegagalan pompa sentrifugal intake B di Perumda Air Minum Tirta Terubuk Kab. Bengkalis.

3. Untuk mengetahui bahwa metode RCM dapat digunakan untuk menganalisa perawatan pompa sentrifugal intake B di Perumda Air Minum Tirta Terubuk Kab. Bengkalis.

4. Membuat usulan perawatan berdasarkan analisa diagram fisbhone/tulang ikan.

\section{Pengambilan Data}

Berdasarkn dokumen-dokumen perawatan pompa sentrifugal intake $\mathrm{B}$ didapatkan data seperti Tabel berikut.

Tabel 2 Potensi Kegagalan

\begin{tabular}{|l|l|l|l|}
\hline No & Potensi Kegagalan & Bulan & Jam \\
\hline 1 & Bearing goyang & 8 & 5.760 \\
\hline 2 & $\begin{array}{l}\text { Impeller } \\
\text { penyok/bengkok }\end{array}$ & 18 & 12.960 \\
\hline 3 & Gland packing bocor & 6 & 4.320 \\
\hline 4 & Rubber coupling & 10 & 7.200 \\
\hline 5 & Shaft (poros) & 15 & 10.800 \\
\hline
\end{tabular}

Hasil Nilai Severity, Occurrence, Detection dan $R P N$ pada komponen Pompa Sentrifugal Intake B.

Tabel 3 Nilai Severity, Occurrence, Detection dan RPN

\begin{tabular}{|l|l|c|c|c|c|}
\hline$N_{0}$ & Potensi Kegagalan & Severity & Occurance & Detection & RPN \\
\hline 1 & Bearing goyang & 8 & 7 & 1 & 56 \\
\hline 2 & Impeller penyokbengkok & 3 & 7 & 6 & 126 \\
\hline 3 & Gland packing bocor & 4 & 8 & 3 & 96 \\
\hline 4 & Rubber coupling rusak & 10 & 10 & 3 & 300 \\
\hline 5 & Shaft (poros) lecet & 2 & 3 & 2 & 36 \\
\hline
\end{tabular}

Tabel.2 menunjukan hasil pemberian sekor Severity, Occurance, Detection. Dalam aspek $\mathrm{S}=$ Severity untuk masing-masing potensi kegagalan proses dan potensi akibatnya dari empat fungsi utama komponen pompa berdasarkan penyebab kegagalan yang terjadi dalam skor 1-10 didapatkan nilai severity tertinggi (nilai 10) pada Raber kopling yang rusak, sedangkan nilai terkecil (nilai 2) jatuh pada empat fungsi komponen pompa. Semangkin besar nilainya, maka semakin tinggi resiko kegagalan sehingga membutuhkan perhatian dan tindakan pencegahan. Langkah selanjutnya adalah penilaian dalam aspek $\mathrm{O}=$ Occurance. Pada hasil pemberian skor dalam aspek $\mathrm{O}=$ Occurance untuk masing-masing potensi kegagalan proses dan potensi akibatnya dari empat fungsi utama komponen pompa berdasarkan pertimbangan yang sama dengan pemberian nilai Severity dalam rangking skor 1-10 didapatkan Nilai Occurance tertinggi (nilai 10) pada fungsi rubber coupling rusak. Hal yang sama dengan hasil penelitian Suryanto Nasution (2019). [2], yang mengatakan nilai 10 adalah nilai kerusakan tertinggi.

Pada tabel.2, diatas dalam rangking skor 110 didapatkan Nilai Detection tertinggi (nilai 6) pada Impeller penyok/bengkok dan shaft (poros) lecet pada pompa. Sedangkan nilai terkecil (nilai 1) jatuh pada bearing goyang pada pompa. Semakin besar nilainya, maka semakin tinggi resiko kegagalan sehingga membutuhkan perhatian dan tindakan pencegahan. Dari hasil penggabungan penilaian Severity, Occurance dan Detection ditempatkan secara bersama-sama. Dari 5 data hasil penilaian S, O dan D dikalikan $(\mathrm{S} \times \mathrm{O} \times \mathrm{D})$. Selanjutkan, hasil perkalian $(\mathrm{S} \times \mathrm{O} \times \mathrm{D})$ diurut berdasarkan rangking dari urutan terbesar sampai yang terkecil sehingga didapatkan satu daftar potensi kegagalan terbesar yaitu kerusakan pada pompa (300). Sedangkan 5 daftar potensi kegagalan dengan nilai terkecil yaitu jatuh pada empat fungsi komponen pompa.

Dari tabel 2. Diatas menunjukan pada nilai RPN yg tertinggi adalah pada rubber coupling rusak (300). Rubber coupling rusak yang di sebabkan terjadinya getaran yang berlebihan, dengan keadaan tanah yang mudah mengalami penurunan maka rubber coupling tidak cocok untuk di gunakan pada pompa sentrifugal intake B di sebabkan kondisi tanah tidak sesuai dengan keadaan yang di butuhkan karena getaran yang berlebih. Maka rubber coupling yang di gunakan harus di ganti dengan menggunakan selendang kopling untuk mencegah terjadi kerusakan akibat kondisi tanah yang mudah menurun. Sedangkan Dari table 5 di atas menunjukan pada nilai RPN yang terkecil adalah pada shaf/poros lecet (36). shaf/poros lecet yang di sebabkan adanya penumpukkan kontoran akibat tidak adanya pembersihan secara terrjadwal untuk menjaga kondisi komponen selalu baik.

Failure Mode and Effects Analysis (FMEA) pada Pompa Sentrifugal Intake B

Dengan metode FMEA ini kita bisa menganalisa permasalahan yang bakal muncul pada suatu produk yang akan dibuat atau suatu proses yang akan dilakukan, kemudian karena masalah yang 
berpotensi muncul sudah ditemukan terlebih dahulu maka kita bisa menentukan tindakan pencegahannya. Dari kacamata dunia industri, istilah FMEA tersebut bisa diartikan sebagai suatu metode analisa potensi kegagalan yang dilakukan sebelum design produk direalisasikan dan atau sebelum produksi massal dimulai.

FMEA merupakan salah satu bentuk analisa kualitatif resiko dan secara umum bertujuan penyusunan. FMEA adalah proses untuk membantu dalam pemilihan desain alternative yang memiliki kehandalan dan keselamatan potensial tinggi, menjamin bahwa semua mode kegagalan yang dapat diperkirakan dan dampak yang ditimbulkannya terhadap kesuksesan operasional sistem telah dipertimbangkan.

Untuk membuat daftar pemeriksaan sistem sebagai analisa kualitatif kehandalan dan ketersediaan, sebagai dokumentasi untuk referensi pada masa yang akan datang untuk membantu menganalisa kegagalan yang terjadi di lapangan serta membantu bila sewaktu-waktu terjadi perubahan desain sebagai data input untuk study banding serta sebagai basis untuk menentukan prioritas pemeliharaan dan perawatan. Salah satu faktor yang penting dalam suksesnya penerapan FMEA adalah (timelines) yaitu melakukan sebelum kegagalan yang terjadi (before the event) adalah dan bukan melakukan sesudah terjadi.

\section{Analisa Data Kerusakan pada Pompa Sentrifugal Intake B}

Hasil pengolahan data pada tabel 4 maka dibuatlah grafik Pareto sebagai mana ditampilkan pada gambar diagram 4 yang menunjukan secara visual urutan potensi kegagalan proses kerusakan komponen pompa dari nilai terbesar sampai dengan nilai terkecil. Informasi ini dijadikan sebagai bahan pertimbangan dalam memutuskan perioritas resiko yang harus diatasi secara efektif. Salah satu yang dapat membantu dalam proses analisa penyebab potensi kegagalan di FMEA adalah dengan diagram isikawa atau "fishbone". Urutan perioritas resiko seperti ditampilkan oleh diagram pareto, penentuan kemungkinan penyebab potensi kegagalan diangkat pada saat penelitian, perioritas utama dalam menentukan masalah potensi kegagalan pada proses kerusakan komponen pompa yang dipilih berdasarkan data grafik pareto. Satu masalah terbesar yang jadi prioritas, prioritas utama dalam menentukan masalah potensi kegagalan pada proses kerusakan komponen pompa yang dipilih berdasarkan diagram pareto. Satu masalah terbesar yang jadi perioritas adalah rubber coupling rusak (300) yang berpotensi menjadi kegagalan proses kerusakan komponen pompa sebagai mana terlihat pada gambar Diagram 2.
Tabel 4 Analisa Data Kerusakan Dengan FMEA

\begin{tabular}{|c|c|c|c|c|c|}
\hline No & Komponen & Model kegagalan & Penyebab kegagalan & Efek kegagalan & $\begin{array}{c}\text { Tindakan yang } \\
\text { Dilakukan }\end{array}$ \\
\hline 1 & Bearing & $\begin{array}{c}\text { Hancurtidak } \\
\text { sempuma }\end{array}$ & $\begin{array}{c}\text { Getaran yang } \\
\text { berilebihan }\end{array}$ & $\begin{array}{c}\text { Hasil kerja pompa tidak } \\
\text { stabi dan bisa } \\
\text { menyebabkan komponen } \\
\text { lain mudah rusak }\end{array}$ & $\begin{array}{l}\text { Ganti dan usahakan } \\
\text { memperkecil getaran }\end{array}$ \\
\hline 2 & Inpeller & $\begin{array}{c}\text { Penyot } \\
\text { (bengkok) }\end{array}$ & $\begin{array}{l}\text { Kavitasi dan kotoran } \\
\text { air yg ikut mengalir }\end{array}$ & $\begin{array}{c}\text { Mengurang kecepatan } \\
\text { debit air }\end{array}$ & $\begin{array}{c}\text { Melakukannperavatan dan } \\
\text { memasang filter/saingan } \\
\text { terhadap air masulk }\end{array}$ \\
\hline 3 & $\begin{array}{l}\text { Gland } \\
\text { packing }\end{array}$ & Bocor & \begin{tabular}{|c|} 
Getaran yang \\
berlebihan dankotorar \\
yang menempel
\end{tabular} & $\begin{array}{l}\text { Tejadinya kebocoranyang } \\
\text { menyebabkan kineja } \\
\text { pompa tidak maksimal }\end{array}$ & $\begin{array}{l}\text { Ganti dan melakukan } \\
\text { pembershan terhadap } \\
\text { kawasan gland packing }\end{array}$ \\
\hline 4 & $\begin{array}{l}\text { Rubber } \\
\text { coupling }\end{array}$ & $\begin{array}{l}\text { Hancur } \\
\text { (rusak) }\end{array}$ & $\begin{array}{c}\text { Hancur akibat getarar } \\
\text { berlebihan }\end{array}$ & $\begin{array}{c}\text { Bisa merusak komponen } \\
\text { lain dan pompa tidak bisa } \\
\text { berfungsi }\end{array}$ & $\begin{array}{c}\text { Ganti dan lakukan } \\
\text { aperbaikan pada lantai agar } \\
\text { di beton untuk mengurang } \\
\text { getaran terha dap pompa } \\
\text { maupun motor. }\end{array}$ \\
\hline 5 & $\begin{array}{l}\text { Shaft } \\
\text { (poros) }\end{array}$ & Lecet & $\begin{array}{c}\text { Penumpulan } \\
\text { kotoran }\end{array}$ & $\begin{array}{c}\text { Kotoran akan merusak } \\
\text { komponen seal didalam } \\
\text { gland packing }\end{array}$ & $\begin{array}{c}\text { Melakukan } \\
\text { pembershan terhadap } \\
\text { poros }\end{array}$ \\
\hline
\end{tabular}

\subsection{Diagram Pareto (Diagram Batang)}

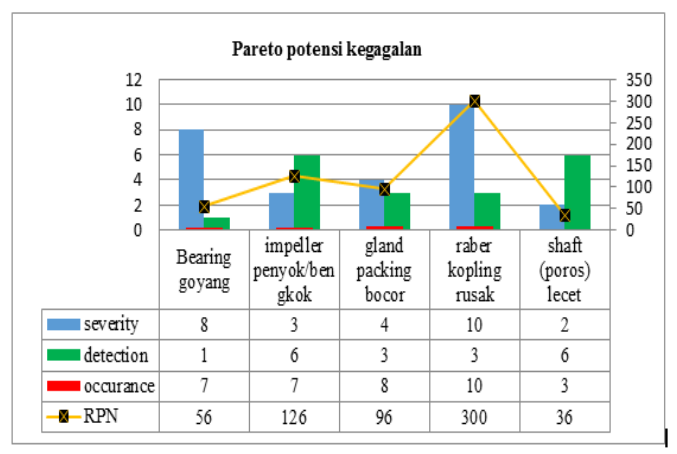

Gambar 4 Diagram Pareto Potensi Kegagalan

\section{Diagram Fishbone (Tulang Ikan)}

Berikut ini adalah diagram sebab akibat yang paling patal kerusakan yaitu kerusakan komponen pompa sentrifugal intake $\mathrm{B}$. Adapun penjelasan Diagram fishbone dapat di lihat pada Diagram di bawah ini.

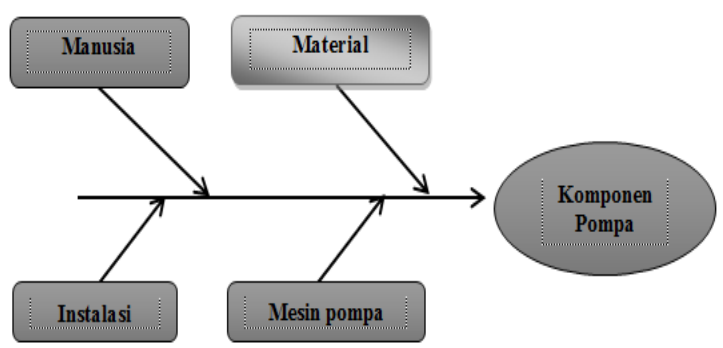

Gambar 5 Sebab Akibat Kerusakan Komponen Pompa. 
Pada gambar 5 diatas diperlihatkan berbagai kemungkinan penyebab potensi kerusakan pada komponen pompa sentrifugal intake B. Pada Diagram fishbone ditunjukan bahwa dari berbagai penyebab ditetapkan kerusakan terhadap komponen pompa yang mengalami kerusakan, yaitu komponen tidak bisa di gunakan lagi.

Recommnded Action :Lakukan perbaikan dengan cara menggantikan komponen dengan yang baru, kemudian melakukan pemasangan komponen sesuai standar yang di tentukan.Kurangi getaran antara pompa dan motor sesuai prosedur dengan menggunakan pengecekan alat vibration meter.

Berikut ini adalah penjelasan sebab akibat kerusakan komponen Pompa Sentrifugal.

\section{Material}

- Sudah mengalami korosi, kerusakan terhadap komponen.

- Jenis material tidak sesuai contohnya seperti rubber coupling dengan kondisi tanah yang mudah menurun maka harus di ganti dengan selendang coupling.

\section{Manusia}

- Tidak mempunyai tekniksi khusus maintenance pompa.

- Dalam pemasangan, maintenance mengalami kekurangan peralatan yang di butuhkan. Namun hanya menggunakan peralatan seadanya.

\section{Mesin pompa}

- Getaran yang berlebihan tidak sesuai dengan prosedur. Seharusnya getaran pada pompa 0.71 $\mathrm{Hz}$ sedangkan getaran yang saya dapatkan pada pompa $10.5 \mathrm{~Hz}$ dan $2.2 \mathrm{~Hz}$.

- Lantai atau pondasi yang sudah mengalami keropos atau berkarat.

\section{Instalasi}

Tidak ada filter atau penyaringan air di pipa masuk, yang menyebabkan batu-batu kecil maupun sampah akan terhisap dan bisa merusak empeller.

Mengalami kekurangan peralatan hanya menggunakan peralatan sederhana untuk melakukan pemasangan komponen pompa.

\section{Usulan Perawatan}

Berdasarkan hasil penelitian antara rata-rata kerusakan komponen kritis dengan kerusakan maka dapat disimpulkan bahwa rata-rata pergantian komponen sebelum kerusakan lebih baik. Maka
Sistem perawatan yang di usulkan diharapkan dapat menurunkan downtime terhadap pompa dari komponen pompa sentrifugal intake B. Sebelum terjadinya kerusakan perlu dilakukan perawatan secara preventif untuk menghindari terjadinya downtime pada saat proses produksi.

Tabel 5 Form perawatan per 1 bulan

\begin{tabular}{|c|c|c|c|c|c|c|}
\hline \multicolumn{7}{|c|}{ From Perarratan 1 Bulan } \\
\hline \multirow[t]{4}{*}{ No } & Mesin Pompa & Pompa & \multicolumn{3}{|c|}{ Kondisi Pompa } & \multirow[t]{4}{*}{ Catatan } \\
\hline & Kode Pompa & Intake B & & & & \\
\hline & \multicolumn{5}{|l|}{ Tanggal } & \\
\hline & $\begin{array}{l}\text { Spesifikasi } \\
\text { Pekerjaan }\end{array}$ & Ketentuan & Cara & Baik & Tidak & \\
\hline 1 & $\begin{array}{l}\text { Priksa getaran pada } \\
\text { pompa }\end{array}$ & $\begin{array}{l}\text { Getaran pompa } \\
\text { mengikuti standar }\end{array}$ & $\begin{array}{l}\text { Hidupkan pompa } \\
\text { cek dengan } \\
\text { menggunakan } \\
\text { vibration meter }\end{array}$ & & & \\
\hline 2 & priksa kondisi raber & $\begin{array}{l}\text { Raber terpasang } \\
\text { dengan sempurma } \\
\text { dan tidak rusak }\end{array}$ & $\begin{array}{l}\text { Cekk ketika pompa } \\
\text { sudah di matikan } \\
\text { lihat kondisi raber }\end{array}$ & & & \\
\hline 3 & $\begin{array}{c}\text { Priksa kondisi gland } \\
\text { packing }\end{array}$ & $\begin{array}{c}\text { Tidak ada } \\
\text { kebocoran yang } \\
\text { berlebihan }\end{array}$ & $\begin{array}{l}\text { Hidupkan pompa } \\
\text { lalu liat kondisi } \\
\text { bocor }\end{array}$ & & & \\
\hline 4 & $\begin{array}{l}\text { Priksa getaran pada } \\
\text { motor }\end{array}$ & $\begin{array}{l}\text { Getaran motor } \\
\text { mengikuti standar }\end{array}$ & $\begin{array}{c}\text { Hidupkan motor cek } \\
\text { dengan } \\
\text { menggunakan } \\
\text { vibration meter }\end{array}$ & & & \\
\hline 5 & $\begin{array}{l}\text { Priksa keamanan } \\
\text { pemasangan motor } \\
\text { utama }\end{array}$ & $\begin{array}{l}\text { Motor utama dapat } \\
\text { di lepas dan di } \\
\text { pasang dengan baik }\end{array}$ & $\begin{array}{l}\text { Cek pada saat akan } \\
\text { melepas motor }\end{array}$ & & & \\
\hline \multirow{2}{*}{\multicolumn{3}{|c|}{ NAMA PEMERIKSA: }} & & & & \\
\hline & & & TTD PEMERIKSA & \multicolumn{3}{|c|}{ TTD KEPALA WORSHOP } \\
\hline
\end{tabular}

Perawatan Preventif yang dilakukan dengan menerapakan perawatan per-bulan terhadap pompa sentrifugal. Perawatan pada Pompa Sentrifugal yang diterapkan terhadap beberapa komponen utama pompa, untuk melakukan perawatan perlu adanya form perawatan yang mana sebagai acuan dan sebagai informasi untuk perawatan yang dilakukan. Form ini juga akan memudahkan dalam menyampaikan informasi riwayat perawatan sehingga mudah untuk dilakukan pengontrolan kinerja pompa sentrifugal. Form perawatan satu bulan ini dibuat untuk komponen utama pompa sentrifugal di Perumda Air Minum Tirta Terubuk Kabupaten Bengkalis.

\section{KESIMPULAN}

Dari hasil penelitian yang dilakukan, maka diperoleh kesimpulan sebagai berikut:

1. Pemeliharaan dengan metode RCM (Realibility Centered Maintenance) didapatkan bahwa nilai 
RPN rubber coupling sebesar 300 sehingga perawatan khusus perlu dilakukan pada ruber copling.

2. Laju kerusakan yang terjadi pada kompenen utama pompa sentrifugal yang mana rubber coupling merupakan kompenen yang sering terjadinya kerusakan, yang mana kerusakan yang dialami adalah pecah/hancur yang diakibatkan getaran yang berlebihan.

\section{DAFTAR PUSTAKA}

[1] Azis, M. T., Suprawhardana, M. S., (2010). Penerapan Metode Reliability Centered Maintenance (RCM) Berbasis Web Pada Sistem Pendingin Primer Di Reaktor Serba Guna Ga. Siwabessy. In Jurnal Forum Nuklir (Vol. 4, No. 1, pp. 81-98).

[2] Nasution Suryanton. (2019) Analisa Kegagalan Cylinder Head Mesin Diesel Komatsu Dengan Menggunakan Metode Failure Mode And Effect Analysis (Fmea) Dimegapower Pltd Bengkalis jurnal teknik mesin 